\title{
Analysis of the reserve generating capacity in unified power system of Russia in terms of adequacy assessment
}

\author{
Dmitry Krupenev ${ }^{1 *}$, Ludmila Lebedeva ${ }^{1}$, Gennady Kovalev ${ }^{1}$, Nikolay Belyaev ${ }^{2}$, Andrey Egorov ${ }^{2}$, Roman Gromov $^{3}$ \\ ${ }^{1}$ Melentiev Energy Systems Institute, 130 Lermontov str., Irkutsk, Russia \\ ${ }^{2}$ Ministry of Energy of Russian Federation, Moscow, Russia \\ ${ }^{3}$ Association "NP Market Council", Moscow, Russia
}

\begin{abstract}
The paper is devoted to a topical issue of determining the required total capacity reserve for a given level of adequacy in the operation of the Interconnected Power System of Russia. This paper places an emphasis on a close interdependence between adequacy and total capacity reserve. The higher the adequacy, the larger the reserve should be. We propose that the adequacy indices, including the probability of failure-free operation, be assessed and calculated based on the requirement to adopt one or another adequacy standard. Moreover, the calculated reserve should be considered complete and necessary, but not normative, to maintain the given level of adequacy.
\end{abstract}

\section{Introduction}

For modern conditions of functioning and development of the Unified Power System (UPS) of Russia, the problem of reserving the generating capacity has become particularly acute and this was facilitated by the following main reasons:

- the current situation in the electric power industry, when, due to the instability in the Russian economy, large surpluses of established generating capacities in a significant part of the out-of-date resources have emerged in the UPS, and therefore are of low reliability, but are on the balance sheet and require maintenance costs;

- despite the presence of excess capacity in the whole of the UPS, reliability in some regional energy nodes is characterized as insufficient;

- flaw introduction of modern equipment diagnostics for repair organization according to the technical condition in power companies;

- the discrepancy between the adopted model of the capacity and electricity market to the existing realities of the functioning of the UPS of Russia, including the lack of incentive mechanisms for replacing obsolete capacity, etc.

Taking into account the above, the question of what level of reservation of generating capacity and its location in the system are most effective is multifaceted. The answer to this question depends on factors such as the technical characteristics of the generating equipment used, the capacity of power transmission networks and electric power, the requirements of consumers to ensure the required level of reliability of their electricity supply, etc. The question of sufficient reserves of electric power systems (EPS) is essential for the economy of each region and the country as a whole, since the development of industries, especially energy-intensive industries, largely depends on the reliability of their electricity supply.

The overestimated level of reliability of EPS leads to additional costs that are shifted to electricity consumers, and inadequate reliability leads to damage for both consumers and energy companies. Therefore, the solution of the problem of optimal reservation of EPS should be based on a sound scientific approach, using specialized software products for analysing the reliability of EPS.

From 2010 to 2016, the utilization factor of installed capacity in the UPS of Russia declined from 53 to 47 percent [1]. Excess capacity in power systems reaches up to $30-40$ percent, from the maximum load. The so-called forced generation in recent years has led to a twofold increase in costs, which have to be compensated by the end user. Only in 2015, they were transferred an additional 19 billion rubles.

In this paper, using the example of the United Power System (UPS) of Siberia, the levels of capacity redundancy in it have been analysed from the standpoint of standard of adequacy standards.

\section{EPS adequacy assessment}

Let's consider the basic moments of the procedure for estimating adequacy of EPS. For EPS, the most acceptable method for estimating the adequacy is a method based on statistical modeling (the Monte Carlo method) [2, 3]. AS a rule, the adequacy estimation is carried out for a one-year period, while every hour of the EPS operation is modeled. In this case, only the basic structure of EPS is considered: generation capacities and 
the backbone network, as the basis for the formation of adequacy (system). To assess the power supply systems of specific consumers, the reliability of the local distribution network must be taken into account.

Let $N-$ a given number of a rally calculated states of EPS. Each state of the EPS is characterized by a set of random states: the working generating capacity, the load value $\bar{y}_{i}^{k}$ in the $i$-th node, the capacity of the transmission lines between the nodes $i$ and $j, i=\overline{1, n}$, $j=\overline{1, n}, i \neq j, k=\overline{1, N}$. The values of these random variables are played out using the Monte Carlo method. To assess the capacity deficit of the generated EPS states, the following problem is solved.

Task variables: $x_{i}$ - the used generation power in node $i, y_{i}$ - the load covered at node $i,-$ the capacity flow from node $i$ to node $j, i=\overline{1, n}, j=\overline{1, n}$.

When assessing the capacity deficit of the $k$-th state of EPS, $k=\overline{l, N}$, it is required to find:

$$
\sum_{i=1}^{n} y_{i} \rightarrow \max
$$

taking into account balance limits

$$
x_{i}-y_{i}+\sum_{j=1}^{n}\left(1-a_{j i} z_{j i}\right) z_{j i}-\sum_{j=1}^{n} z_{i j}=0, \quad i=\overline{1, n}, i \neq j \text {, }
$$

and linear restrictions-inequalities on variables.

$$
\begin{gathered}
y_{i} \leq \bar{y}_{i}^{k}, i=\overline{1, n}, \\
x_{i} \leq \bar{x}_{i}^{k}, i=\overline{1, n}, \\
z_{i j} \leq \bar{z}_{i j}^{k}, i=\overline{1, n}, j=\overline{1, n}, i \neq j, \\
y_{i} \geq 0, \quad x_{i} \geq 0, \quad z_{i j} \geq 0, i=\overline{1, n}, j=\overline{1, n}, i \neq j,
\end{gathered}
$$

where $a_{i j}$ is a given positive coefficients of specific capacity losses when it is transferred from node $i$ to node $j, i \neq j$.

After determining the deficits in EPS, during the accounting period such basic indexes of adequacy as: - probability of failure-free (no-deficit) operation of EPS;

- the mathematical expectation (m.e.) of undersupply of electricity to consumers;

- the ratio of electricity supply to consumers;

- the values of the estimated reserves of various types for the nodes and the system as a whole;

- energy-reliability characteristics of ties;

- dual (objectively determined) estimates of the deficiency of the main resources (capacity of generators by nodes and transfer capabilities of ties).

\section{The practice of EPS adequacy indexes rating}

To date, there are no approved standards for adequacy indexes for the UPS of Russia. There are recommended values of the probability of failure-free (no-deficit) work of consumers, prescribed in the "Energy Strategy of Russia 2030". In accordance with this document, UPS of Russia at the level of 2030 should ensure the probability of failure-free operation of electricity consumers at the level of 0.9997 . Moreover, there are two intermediate stages - 2015 and 2020, for which the probability of failure-free operation should be at the level of 0.999 and 0.9991 , respectively. At the same time, it is not specified how to interpret this standard for the UPS as a whole or for the calculated nodes of the UPS.

The standard indicator of adequacy at the level of the main structure of the UPS of Russia (the calculated energy nodes of the UPS and interconnections) is well known - the probability of a no-deficit work, equal to 0.996. This indicator is justified in [4] for the conditions of functioning and development of the energy system of the USSR.

In the practice of controlling the power systems of a number of foreign countries, to ensure their reliability and the required level of reserves of generating capacity, a probabilistic approach is applied when assessing the adequacy and the standards of probability reliability indexes are used [5-10]. Here are some examples:

- in France, the criterion of adequacy is the values of the reliability index LOLH (loss of load hours) - the expected number of days in a year during which there is a capacity deficit. It is believed that EPS works reliably, if LOLH does not exceed 3 hours per year;

- in the Netherlands, the standards of value LOLH is 4 hours per year;

- in the Scandinavian countries, the reliability criterion of the capacity system is LOLP (loss of load probability) - the probability of a capacity deficit in a small time interval, usually during the maximum load period, which is $0.001 \%$ per year;

- LOLE (Loss of Load Expectation) $=0.1$ day / year is adopted in the USA.

\section{Analysis of UPS Siberia adequacy at the level of 2015}

Investigation of the level of reservation of generating capacity was carried out at the UPS of Siberia.

The study consisted of the following stages:

1. Estimation of adequacy of the UPS of Siberia.

2. Based on the probability of failure-free operation at the nodes of the UPS of Siberia and the accident rate of the generating units, an alternate shutdown of generating units with the highest accident rate at nodes with the highest probability of failure-free operation was carried out.

3. Improving the probability of failure-free operation at the nodes of the UPS of Siberia to levels of 0.9997 ; $0.999 ; 0.996$. 
The calculations were carried out using the 12-node scheme of the UPS of Siberia, shown in fig. 1.

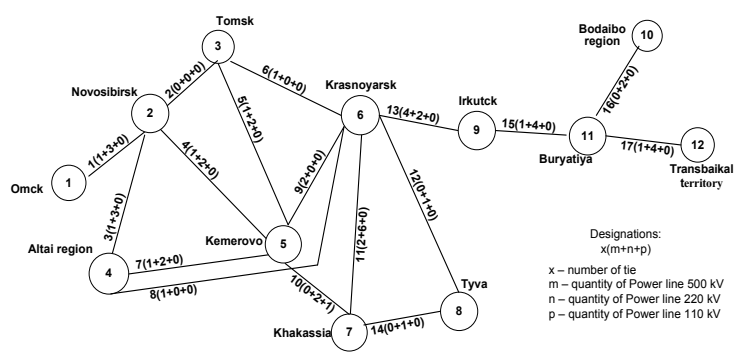

Fig. 1. Calculated schema UPS Siberia

The presentation of the UPS of Siberia on energy units was made on the basis of regional UPS. The external ties of the UPS of Siberia are accepted open, and all the initial data for the calculation were adopted at the level of 2015 .

In table 1 shows a brief description of the nodes of the UPS of Siberia [11-13].

Table 1. Brief description of the nodes.

\begin{tabular}{|c|c|c|c|c|c|}
\hline \multirow{2}{*}{ № } & \multirow{2}{*}{ Node name } & \multirow{2}{*}{$\begin{array}{c}\text { Absolute } \\
\text { maximum of } \\
\text { load, MW }\end{array}$} & \multirow{2}{*}{$\begin{array}{c}\text { Available } \\
\text { capacity, } \\
\text { MW }\end{array}$} & \multicolumn{2}{|c|}{ Total own reserve } \\
\cline { 5 - 6 } & & 1782 & 1479 & -303 & -17 \\
\hline 1 & Omsk & 2690 & 2730 & 40 & 1,49 \\
\hline 2 & Novosibirsk & 1302 & 918 & -384 & $-29,49$ \\
\hline 3 & Tomsk & 1884 & 1444 & -440 & $-23,35$ \\
\hline 4 & Altai region & 4535 & 5028 & 493 & 10,87 \\
\hline 5 & Kemerovo & 6235 & 12006 & 5771 & 92,56 \\
\hline 6 & Krasnoyarsk & 2155 & 5430 & 3275 & 151,97 \\
\hline 7 & Khakassia & 152 & 40 & -112 & $-74,01$ \\
\hline 8 & Tyva & 7570 & 12550 & 4980 & 65,79 \\
\hline 9 & Irkutsk & 90 & 20 & -70 & $-77,78$ \\
\hline 10 & Bodaibo & 945 & 898 & -47 & $-4,97$ \\
\hline 11 & Buryatia & 1260 & 1156 & -104 & $-8,25$ \\
\hline 12 & $\begin{array}{c}\text { Transbaikal } \\
\text { territory }\end{array}$ & 1304 & 44,23 \\
\hline \multicolumn{2}{|c|}{ Siberia UPS } & $30298,6^{\text {a }}$ & 43699 & 13400 & 49 \\
\hline
\end{tabular}

a According to the UPS of Siberia, the combined maximum of the load is indicated (the sum of annual maxima for the nodes is $30,600 \mathrm{MW}$ ).

As can be seen from table 1 , the total own reserve in the UPS of Siberia is at the level of $44 \%$, which exceeds the recommended standard (12\%) [14] by $32 \%$. The data on the transmission capacities of the UPS of Siberia are given in table
Table 2. The values of the transmission capacities of the UPS of Siberia.

\begin{tabular}{|c|c|c|}
\hline $\begin{array}{c}\text { Tie } \\
\text { number }\end{array}$ & $\begin{array}{l}\text { Nodes adjacent to tie (node } \\
\text { number and name) }\end{array}$ & $\begin{array}{c}\text { Transfer } \\
\text { capabilities of } \\
\text { tie }(\mathrm{MW})\end{array}$ \\
\hline 1 & Omsk - Novosibirsk & 1305 \\
\hline 2 & Novosibirsk - Altai region & 1440 \\
\hline 3 & Novosibirsk - Kemerovo & 950 \\
\hline 4 & Tomsk - Kemerovo & 1170 \\
\hline 5 & Tomsk - Krasnoyarsk & 780 \\
\hline 6 & Altai region - Kemerovo & 950 \\
\hline 7 & Altai region - Krasnoyarsk & 850 \\
\hline 8 & Kemerovo - Krasnoyarsk & 1560 \\
\hline 9 & Kemerovo - Khakassia & 1650 \\
\hline 10 & Krasnoyarsk - Khakassia & 3400 \\
\hline 11 & Krasnoyarsk - Tyva & 135 \\
\hline 12 & Krasnoyarsk - Irkutsk & 3630 \\
\hline 13 & Khakassia - Tyva & 135 \\
\hline 14 & Irkutsk - Buryatia & 885 \\
\hline 15 & Bodaibo - Buryatia & 66 \\
\hline 16 & Buryatia - Transbaikal territory & 410 \\
\hline
\end{tabular}

When assessing the reliability, each tie is represented by a set of power lines entering into it with characteristic accidents and capacity loss factors. The transmission capacities of individual transmission lines was taken from [15] with allowance for given permissible limitations on throughput capacities in sections.

In table 3 shows the results of calculations of the adequacy indexes. 
Table 3. Dynamics of the change in the probability of failure-free operation and the mathematical expectation of an undersupply of electricity at the nodes of the UPS of Siberia.

\begin{tabular}{|c|c|c|c|c|c|c|c|c|}
\hline \multirow{3}{*}{ Node name } & \multicolumn{8}{|c|}{ Variants } \\
\hline & \multicolumn{2}{|c|}{ initial } & \multicolumn{2}{|c|}{$P=\mathbf{0 , 9 9 9 7}$} & \multicolumn{2}{|c|}{$\rho_{=0,999}$} & \multicolumn{2}{|c|}{$\mathscr{P}=\mathbf{0 , 9 9 6}$} \\
\hline & pp & $\begin{array}{l}E_{\text {und }}, \\
\text { MW·h }\end{array}$ & pp & $\begin{array}{l}E_{\text {und }}, \\
\text { MW·h }\end{array}$ & $\rho$ & $\begin{array}{l}E_{\text {und }}, \\
\text { MW·h }\end{array}$ & gp & $\begin{array}{l}E_{\text {und }}, \\
\text { MW·h }\end{array}$ \\
\hline Omsk & 0,999977 & 16,8 & 0,999748 & 336,1 & 0,999097 & 1271,9 & 0,996104 & 5993,2 \\
\hline Novosibirsk & 0,999999 & 0 & 0,999931 & 11,3 & 0,999682 & 66,5 & 0,998381 & 329,9 \\
\hline Tomsk & 0,999999 & 0 & 0,999926 & 20,8 & 0,999634 & 171,6 & 0,998197 & 804,7 \\
\hline Altai region & 0,999999 & 0 & 0,999927 & 22,4 & 0,999652 & 109,7 & 0,998156 & 682,1 \\
\hline Kemerovo & 0,999999 & 0 & 0,999933 & 9,3 & 0,999665 & 78,1 & 0,998233 & 460,3 \\
\hline Krasnoyarsk & 0,999999 & 0 & 0,999933 & 20,7 & 0,999637 & 117,1 & 0,998200 & 634,2 \\
\hline Khakassia & 0,999999 & 0 & 0,999946 & 5,3 & 0,999791 & 92,1 & 0,999002 & 391,5 \\
\hline Tyva & 0,999980 & 11,5 & 0,999893 & 42,3 & 0,999584 & 134,6 & 0,998123 & 551,1 \\
\hline Irkutsk & 0,999999 & 0 & 0,999936 & 9,4 & 0,999647 & 134,5 & 0,997985 & 2106,4 \\
\hline Bodaibo & 0,8 & 7495,7 & 0,8 & 7670,3 & 0,8 & 8071,1 & 0,8 & 9776,0 \\
\hline Buryatia & 0,999989 & 1,2 & 0,999736 & 175,8 & 0,999074 & 675,6 & 0,996158 & 3045,0 \\
\hline Transbaikal territory & 0,991265 & 5607 & 0,990816 & 6222,7 & 0,989769 & 7796,8 & 0,985308 & 13719 \\
\hline
\end{tabular}

As can be seen from table 3 , the probability of failure-free (no-deficiency) operation at the nodes of the UPS of Siberia in the initial variant is at a high level, practically at all nodes, except for the Transbaikal territory and the Bodaibo power node. Reliability of power supply in problem nodes can be increased either by strengthening ties with other nodes or by building generating capacities directly at these nodes. After applying the above-described approach to lowering the generating capacity for different standard values of the probability of failure-free operation, it was possible to significantly reduce the generation capacity reserves and finally it was found that in the UPS of Siberia, it is sufficient to maintain a reserve capacity $R=4293$ MW for reliable operation (ensuring the probability of a no-deficit operation at 0.996 ), having carried out for 9107 MW connection of additional load power in general for UPS of Siberia.

In table 4 shows the values of power reserves in the nodes of the UPS of Siberia and for the system as a whole, which were obtained at each step.
Table 4. The values of power reserves of UPS Siberia for different levels of adequacy.

\begin{tabular}{|c|c|c|c|c|c|c|c|c|}
\hline \multirow{3}{*}{ Node name } & \multicolumn{8}{|c|}{ Variant } \\
\hline & \multicolumn{2}{|c|}{ 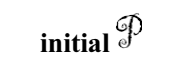 } & \multicolumn{2}{|c|}{$\int=\mathbf{0 , 9 9 9 7}$} & \multicolumn{2}{|c|}{$\mathscr{P}=\mathbf{0 , 9 9 9}$} & \multicolumn{2}{|c|}{$\mathscr{\rho}=\mathbf{0 , 9 9 6}$} \\
\hline & MW & $\%^{b}$ & MW & $\%$ & MW & $\%$ & MW & $\%$ \\
\hline Omsk & -303 & -17 & -303 & -17 & -303 & -17 & -303 & -17 \\
\hline Novosibirsk & 40 & 1,49 & 40 & 1,49 & 40 & 1,49 & 40 & 1,49 \\
\hline Tomsk & -384 & $-29,49$ & -384 & $-29,49$ & -384 & $-29,49$ & -384 & $-29,49$ \\
\hline Altai region & -440 & $-23,35$ & -440 & $-23,35$ & -440 & $-23,35$ & -440 & $-23,35$ \\
\hline Kemerovo & 493 & 10,87 & 493 & 10,87 & 493 & 10,87 & 493 & 10,87 \\
\hline Krasnoyarsk & 5771 & 92,56 & 1223 & 19,62 & 788 & 12,64 & 788 & 12,64 \\
\hline Khakassia & 3275 & 151,97 & 2870 & 133,18 & 2870 & 133,18 & 2870 & 133,18 \\
\hline Tyva & -112 & $-74,01$ & -112 & $-74,01$ & -112 & $-74,01$ & -112 & $-74,01$ \\
\hline Irkutsk & 4980 & 65,79 & 1894 & 25,02 & 1908 & 25,2 & 1261 & 16,66 \\
\hline Bodaibo & -70 & $-77,78$ & -70 & $-77,78$ & -70 & $-77,78$ & -70 & $-77,78$ \\
\hline Buryatia & -47 & $-4,97$ & -47 & $-4,97$ & -47 & $-4,97$ & -47 & $-4,97$ \\
\hline $\begin{array}{l}\text { Transbaikal } \\
\text { territory }\end{array}$ & -104 & $-8,25$ & -104 & $-8,25$ & -104 & $-8,25$ & -104 & $-8,25$ \\
\hline UPS Siberia $^{c}$ & 13400 & 44,23 & 5361 & 17,7 & 4940 & 16,31 & 4293 & 14,17 \\
\hline
\end{tabular}

${ }^{\mathrm{b}} \%$ of maximum load

c The values of capacity reserves in the system as a whole are related to the combined maximum of the load (30298.6 MW), and the nodes to their own.

Fig. 2 graphically shows the dependence of the required reserve to ensure the required level of reliability of the EPS under study. It follows from the figure that the sharp increase in the required reserve begins with the probability of a no-deficit work of 0.9997. 


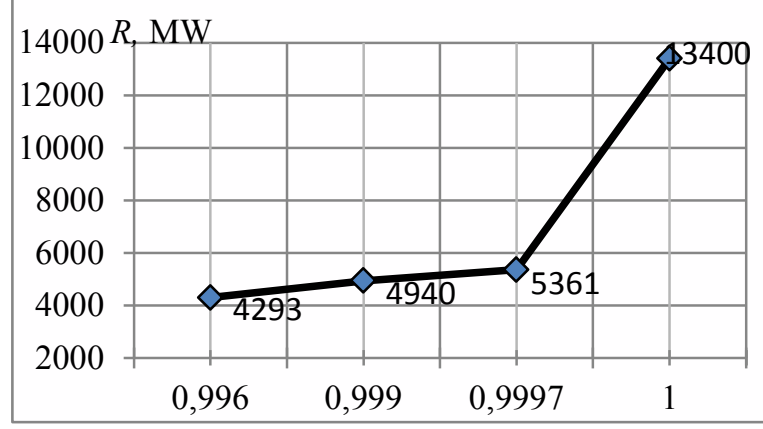

Fig. 2. Dependence of the required reserve on the reliability index.

\section{Problems in the collection and processing of initial information}

To assess the adequacy of EPS, a vast amount of information characterizing the EPS under investigation is needed. The completeness and reliability of the initial information depends on the reliability of the received indexes of the adequacy of EPS. Below is an analysis of the basic principles of the collection of initial data and problems that arose when collecting information on the UPS of Siberia for this work.

A. The design scheme of EPS (equivalent power nodes and ties between them). The design scheme should be designed in such a way that each power node represented in it is concentrated, i.e. within the node there should be no restrictions on capacity flows in any likely regimes.

In this study, the breakdown of the calculation scheme was carried out according to the areas of responsibility of the regional dispatch offices. The only exception is the Tomsk and Tyva power systems, as well as the Bodaibo power node.

B. Characteristics of generating equipment in the calculation units of EPS. For the assessment of adequacy EPS it is necessary to have the following information: the composition of generating units in EPS nodes, the unit available capacity, the standard for scheduled (major, mid-life and current) repairs, the failure rate of each unit.

During the research, the following problems were identified: information on the total available capacity of the node in different sources is different. There are no data on the accident rate of generating units. Thus, in the reporting data the indicator "Total time spent in repair (planned, unplanned) for the reporting year, hours" is given. From this indicator it is difficult to find out what time the unit was in routine repair, therefore it is necessary to oblige generating companies to correctly separate planned and unplanned repairs in the reporting data. In this study, the issue of the failure rate of generating units was solved as follows:

1. From the indicator "Total time spent in repair (scheduled, unscheduled) for the reporting year, hours" for 4 years from 2012 to 2015, the mathematical expectation (m.e.) of this indicator for each unit was found.
2. Using the data of SB 34.04.181-2003 according to the standards of scheduled repairs of generating units, the average duration of idle time of each unit in scheduled repairs per year was found.

3. The difference between m.e. "The total time spent in repair (scheduled, unscheduled) for the reporting year, hours" and the average duration of idle time of each unit in scheduled repairs per year is taken as the total time of the emergency idle of generating units for the year.

When processing the data on the accident rate of the generating equipment in the UPS of Siberia, the units were identified which, in emergency repairs (idle times), are more than 2500 hours per year, which indicates either a critical condition of these units or inaccurate data provided by generating companies.

C. Information on loading graphs in the nodes of EPS. To conduct the study, it is necessary to have the characteristic daily and annual graphs of the monthly maximum loads in each of the nodes, the root-meansquare deviations of the loads from the predicted graphs. When compiling a design scheme for EPS based on clustering, the boundaries of some nodes will not correspond to the boundaries in which regional power systems are located, therefore additional information on load schedules of these nodes is needed to estimate the adequacy for such schemes.

\section{Conclusion}

In the current conditions of the functioning of the UPS of Russia, there are problems that affect, namely, reduce the efficiency of its operation. One of the problems is unreasonable excess of generating capacity, which lead to economically inefficient operation of the UPS, including the increase in the cost of electricity for consumers and other negative consequences. To determine the values of the excess generating capacity, we propose an approach based on the use of ambiguous estimates obtained after solving the problem of minimizing the power deficit at the nodes for given standard values of the adequacy indexes of EPS.

Within the framework of the conducted studies, the level of redundancy of generating capacity in the UPS of Siberia was analysed. For the analysis of the dynamics of changes in the reservation level, several standard values of the probability of failure-free (no-deficit) operation of the UPS were accepted: $0.9997 ; 0.999 ; 0.996$; As a result, it was found that the growth of the necessary reserve of generating capacity is moderate to 0.99960.9997, after which the growth rate of its growth is significantly increased.

It should also pay special attention to the fact that the accuracy of calculations is largely determined by the quality of the source information, the completeness and reliability of which at the current stage remain problematic. It takes a lot of work to create at the federal level an infrastructure for the collection and processing of primary information on the parameters of the operation of EPS and equipment. This will also help to increase the validity of decisions taken to ensure adequacy. 


\section{References}

1. E. Voskanyan, Newspaper "Ene. \& Ind. of Rus.", No. 08, 292 (2016)

2. D.S. Krupenev, S.M. Perzhabinsky, Contr. of lar. sys., issue 54, Pp. 166-178. (2015)

3. G.F. Kovalev, L.M. Lebedeva Reliability of electric power systems, Nauka, 224 (2015)

4. I. M. Wolkenau, A. N. Zeiliger, L. D. Khabachev, Economics of the formation of electric power systems, Energia, 319 (1981)

5. Yu. N. Kucherov, Yu. G. Fedorov, Electro. Electr. eng., elec. pow/ ind., electrotech. ind. № 6, p. 2-11. (2010)

6. The concept of determining the reserves of installed (available) capacity in the UES of Russia, necessary to meet the public needs for reliable and sustainable supply of electrical energy (CRA Project No. D16525) / (Charles river Associates, John Hancock Tower 200, Clarendon Street, I-33, Boston, Massachusetts, 0211, USA,) and Melentiev Energy Systems Institute of Siberian Branch of the Russian Academy of Sciences (ESI SB RAS), Lermontov Street, 130, 664033, Irkutsk, Russia. (2011)

7. K. Uhlen D. Cirio, L. Haarla and oth., IEA ENARD CIGRE 43-th Session, pub. C4-305 (2010)

8. Grid master plan, Nordel, Access at: http://www.pfbach.dk/firma_pfb/historien/data_files/nor dic_grid_master_plan_2008.pdf, (2008).

9. Generation adequacy report on the electricity supply demand balance in France, RTE. Access at: http://www.rte-france.com/en/article/forecast-

assessment-electricity-supply-demand-balance, (2009)

10. Reliability Standarts for the Bulk Electric Systems of North America. NERC, 1010 http://www.nerc.com/files/ Reliability_Standards_Complete_Set.pdf, (2008)

11. Scheme and program for the development of the Interconnected Power System of Russia for 2016-2022 / Order No. 147. of the Ministry of Energy of Russia from March 1, (2016)

12. Report on the functioning of the Interconnected Power System of Russia in 2015 / System Operator of the Interconnected Power System, 40 (2015)

13. Scheme and program for the development of the electric power industry of the Irkutsk region for 20172021. / Approved by the decree of the Governor of the Irkutsk region No. 257-ug. of October 17, (2016)

14. Methodical recommendations on designing the development of power systems / CO 153-34.20.1182003, Approved by Order of the Ministry of Energy of Russia of 30.06.03 № 281e., (2003)

15. Handbook on the design of electrical networks / Ed. D. L. Faibisovich. - 4-th ed., alteration and additional. Moscow: ENAS, 376, 2012 